\title{
Inhibition of the bronchial response to respiratory heat exchange by increasing doses of terbutaline sulphate
}

\author{
PM O'BYRNE, M MORRIS, R ROBERTS, FE HARGREAVE \\ From the Firestone Regional Chest and Allergy Unit, Department of Medicine, St Joseph's Hospital, and McMaster \\ University, Hamilton, Ontario, Canada
}

ABSTRACT Ten asthmatic patients inhaled terbutaline sulphate $(250,500$, or $1000 \mu \mathrm{g})$ or placebo on separate days, double blind and in random order, 30 minutes before isocapnic hyperventilation induced by cold air inhaled in doses that increased in a precisely controlled manner. The respiratory heat exchange (RHE) was calculated for each level of ventilation and the results were expressed as the RHE causing a fall in $\mathrm{FEV}_{1}$ of $10 \%\left(\mathrm{PD}_{10} \mathrm{RHE}\right)$. The $\mathrm{PD}_{10} \mathrm{RHE}$ after placebo was highly reproducible. After terbutaline inhalation there was a highly significant shift in the RHE dose-response curves to the right and a trend towards a linear increase in $\mathrm{PD}_{10} \mathrm{RHE}$ with increasing doses of terbutaline. The subjects who were most responsive to the RHE required more terbutaline to inhibit the response completely. The results indicate that RHE dose-response curves are a precise method to examine the effects of drugs on hyperventilationinduced asthma, that increasing doses of terbutaline can produce increasing protection, and that the degree of protection is dependent on the level of increased bronchial responsiveness to RHE.

Inhibition of exercise-induced asthma by premedication with an inhaled $\beta$-adrenoceptor agonist is an important strategy in the treatment of asthma. Inhaled $\beta$-agonists have been shown to be more effective than other medications in blocking the bronchoconstrictor response to exercise.' Previous studies, however, have generally examined the effect of a single dose of a $\beta$-agonist on the response to one exercise stimulus. ${ }^{23}$ Doctors usually advise their patients to use one dose (usually two puffs) before exercise without knowing whether a smaller dose would be sufficient or a larger dose more effective.

The elegant work of Deal and colleagues has shown that the inciting stimulus for exercise-induced bronchoconstriction is respiratory heat exchange. ${ }^{4}$ The bronchoconstrictor response to exercise is the same as the response to isocapnic hyperventilation causing the same amount of respiratory heat exchange. ${ }^{5}$ Respiratory heat exchange dose-response curves can be constructed by the use of isocapnic hyperventilation induced by subfreezing air, ${ }^{6}$ which should allow a more precise examination of the effects of drugs on exercise-induced asthma.

We have examined the effect of three doses of inhaled terbutaline sulphate $(250,500$, and $1000 \mu \mathrm{g})$ on the dose-response curves for isocapnic hyperventilation induced by subfreezing air in 10 asthmatic patients.

Address for reprint requests: Dr FE Hargreave, Firestone Regional Chest and Allergy Unit, St Joseph's Hospital, 50 Charlton Avenue East, Hamilton. Ontario. Canada L8N IY4.

\section{Methods}

Ten adults with asthma and no other chest disease were selected from the staff and patients attending the Firestone Regional Chest and Allergy Unit at St Joseph's Hospital (table 1). All subjects had episodic dyspnoea and wheezing and a fall in forced expiratory volume in one second $\left(\mathrm{FEV}_{1}\right)$ of $20 \%$ or more after isocapnic hyperventilation induced by subfreezing air. Nine were atopic as indicated by wheal and flare responses to allergy prick tests with 16 common allergen extracts. At the time of the study symptoms of asthma did not disturb sleep and FEV , was greater than $75 \%$ of the predicted normal value. Respiratory infection or exposure to allergens to which

Table 1 Characteristics of the subjects

\begin{tabular}{llllcl}
\hline $\begin{array}{l}\text { Subject } \\
\text { No }\end{array}$ & Sex & $\begin{array}{l}\text { Age } \\
(y)\end{array}$ & $\begin{array}{l}\text { Height } \\
(\mathrm{cm})\end{array}$ & $\begin{array}{l}\text { Atopic } \\
\text { state* }\end{array}$ & Treatment \\
\hline 1 & M & 32 & $187 \cdot 9$ & 9 & S not daily \\
2 & F & 39 & $163 \cdot 8$ & 0 & S not daily \\
3 & M & 29 & $178 \cdot 0$ & 4 & S 400 \\
4 & F & 21 & $157 \cdot 5$ & 13 & S 400 B 400 \\
5 & F & 34 & $152 \cdot 4$ & 4 & S not daily \\
6 & F & 38 & $166 \cdot 4$ & 2 & S not daily \\
7 & F & 34 & $170 \cdot 2$ & 6 & S not daily \\
8 & M & 30 & $177 \cdot 8$ & 3 & S not daily \\
9 & F & 22 & $165 \cdot 1$ & 3 & S not daily \\
10 & M & 24 & $180 \cdot 3$ & 1 & S not daily \\
\hline
\end{tabular}

*Number of positive wheal and flare responses in prick skin tests with 16 common allergen extracts.

S-salbutamol; B-beclomethasone dipropionate (both $\mu \mathrm{g}$ daily). 
the subjects were sensitised had not occurred for at least six weeks. An inhaled bronchodilator was used daily by two subjects and beclomethasone dipropionate by one of these. All other patients required inhaled bronchodilator less than once daily (table 1). The study was approved by the hospital research committee and all the subjects gave informed written consent.

Each subject attended the laboratory at the same time of day on five days within two weeks. On each day inhaled bronchodilator was withheld for at least eight hours. After arrival at the laboratory subjects rested for 30 minutes, then spirometry was performed with a Collins $9 \mathrm{~L}$ water spirometer; three measurements of $\mathrm{FEV}_{1}$ were made at intervals of one minute and vital capacity was measured once. Four puffs of the test medication were inhaled, three different metered-dose inhalers being used to give the appropriate dose of test medication on each study day. The inhalers were held $3 \mathrm{~cm}$ from the wide-open mouth, the subject exhaled to functional residual capacity, the inhaler was activated just after the onset of a five-second inspiration to total lung capacity, and then the breath was held for 10 seconds. Placebo was given on two days and terbutaline sulphate $250 \mu \mathrm{g}, 500 \mu \mathrm{g}$, and $1000 \mu \mathrm{g}$ on the other three days, double blind and in a balanced random order. After 30 minutes $\mathrm{FEV}_{\text {, }}$ was measured again and isocapnic hyperventilation induced by subfreezing air was started.

Isocapnic hyperventilation was carried out by the method described by O'Byrne et al. ${ }^{6}$ Cold dry air $\left(-18^{\circ} \mathrm{C}, 0 \%\right.$ relative humidity) was generated by a heat exchanger and was inhaled in amounts that doubled with each increment $(7.5,15,30$, and $60 \mathrm{l} / \mathrm{min}$ and at maximum voluntary ventilation) for three minutes at intervals of five minutes. Carbon dioxide was added to the inhaled air to keep the subject eucapnic during each period of hyperventilation. The response was measured by change in $\mathrm{FEV}_{1}$ from the lowest baseline value at 0.5 and 1.5 minutes after each inhalation. If there was a fall in $F E V_{1}$ the measurement was repeated at 3 minutes, and subsequently at 2-minute intervals if necessary, until the lowest value was recorded. Once the $\mathrm{FEV}_{1}$ started to improve the subject received the next inhalation of cold air. Inhalations were discontinued once the $\mathrm{FEV}_{\mathrm{l}}$ had fallen by $20 \%$ or after the maximum voluntary ventilation. The respiratory heat exchange (RHE) in kilocalories/minute $(\mathrm{kcal} / \mathrm{min})$ was calculated for each level of ventilation by the formula RHE $=\mathrm{VE}(\mathrm{HC}[\mathrm{Ti}-\mathrm{Te}]$ $+\mathrm{HV}[\mathrm{WCi}-\mathrm{WCe}])$. where $\mathrm{VE}=$ minute ventilation $(1 / \mathrm{min}), \mathrm{HC}=$ heat capacity of air $(0.000304 \mathrm{kcal} / \mathrm{min})$, $\mathrm{Ti}=$ inspired air temperature $\left({ }^{\circ} \mathrm{C}\right), \mathrm{Te}=$ expired air temperature $\left({ }^{\circ} \mathrm{C}\right), \mathrm{HV}=$ latent heat of vapourisation of water $(0.00058 \mathrm{kcal} / \mathrm{mg}), \mathrm{WCi}=$ water content of inspired air $(\mathrm{mg} / \mathrm{l})$, and WCe $=$ water content of expired air $(\mathrm{mg} / \mathrm{l})$. The inspired air was dry. Expired air was assumed to be fully saturated ${ }^{7}$ at the expired temperature and the water content was obtained from standard saturation temperature relationships. ${ }^{8}$ The response was expressed of the provocation dose of RHE to cause a falf in $\mathrm{FEV}_{1}$ of $10 \%\left(\mathrm{PD}_{10} \mathrm{RHE}\right)$ and was obtained from the log dose-response curve by linear interpolation of the last twon points. $^{6}$

ANALYSIS

A randomised block design was used in this experiment Each subject in the study represented a homogeneous block within which each of the five treatments (two placebo, and three active doses) are contrasted. The appropriate analytical approach was a two-way analysis ofo variance.

In the analysis" of the data three questions were considered: (1) What was the reproducibility of $\mathrm{PD}_{1 \sigma}$ RHE? (2) Did terbutaline decrease responsiveness to hyperventilation and did the effects show a dose-respons@ relationship? (3) Did those subjects most responsive to the stimulus require a higher dose of terbutaline to inhibit the response than the less responsive subjects?

Reproducibility was determined from within-subjecto and between-subject variance in the two $\mathrm{PD}_{10}$ RHE determinations after placebo inhalation and was quantio fied in terms of the intraclass correlation. ${ }^{9}$ The effect of the drug on $P_{10}$ RHE was examined initially to deteco any difference between the five treatments, and then linear contrast ${ }^{10}$ was used to compare placebo with active preparations and a second contrast to assess whether the्ठ dose-response relationship was linear. Analysis o $\mathrm{B}$ covariance $^{11}$ was used to adjust the observed treatmen effect for differences in baseline $\mathrm{FEV}_{1}$. The proportion of subjects protected by terbutaline in the groups showing high and low initial responsiveness was compared with Fisher's exact test.

\section{Results}

The mean baseline $\mathrm{FEV}_{1}$ was greater than $90 \%$ of predicted normal and did not differ significantly on the five study days (table 2). The mean increases in FEV after placebo on the two occasions were similar (table 2) The mean increases in $\mathrm{FEV}_{1}$ after terbutaline and placebos inhalation were significantly different $(\mathrm{F} 1,36=14 \cdot 37$, $\mathrm{R}$ $<0.001$ ) (table 3). There was, however, no evidence of bronchodilator dose-response relationship with increas $\omega$ ing doses of terbutaline $(\mathrm{F} 1,36=0 \cdot 56, \mathrm{p}>0 \cdot 1)($ table 3$)$ These results were unchanged after covariance adjusto을 ment for the baseline FEV, level.

The response to isocapnic hyperventilation induced by subfreezing air on the two placebo days was the same. The within-subject standard deviation of $\mathrm{PD}_{10}$ RHE was $0 \cdot 2$ 居 on the $\log _{e}$ scale and the between-subject standar $\mathbb{P}$ deviation was 0.78 . The intraclass correlation was $0.93 \%$ thus $93 \%$ of the total variation in $\mathrm{PD}_{10}$ RHE reflected rea differences between subjects (signal) as opposed to inherent imprecision of the measurement (noise). Terbutae 
Table 2 Results of inhalation tests

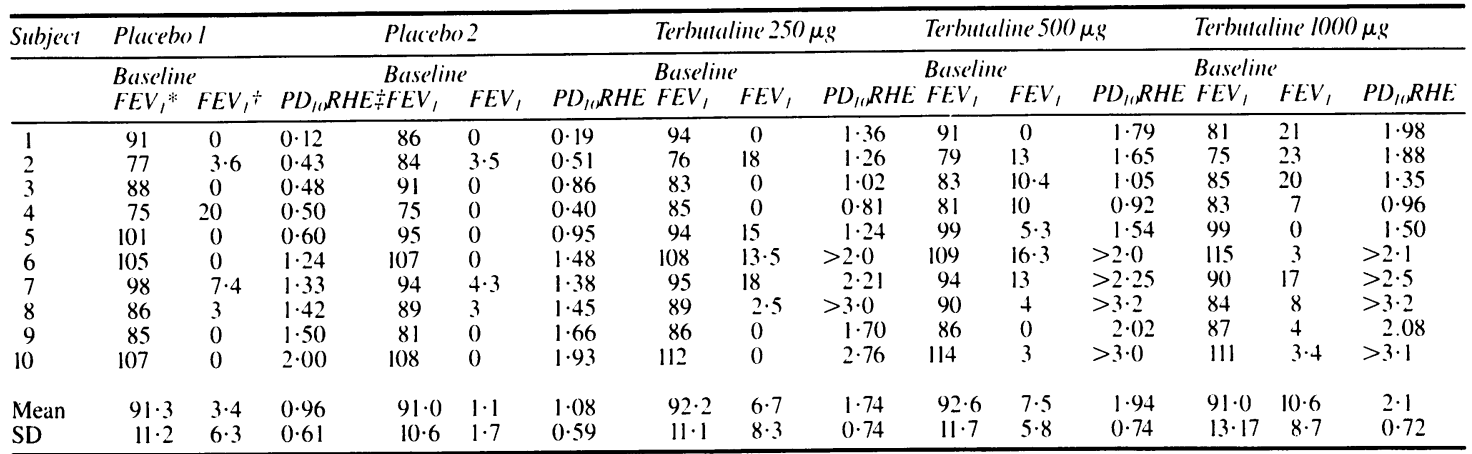

*Baseline FEV expressed as percentage of predicted normal.

†Percentage increase in FEV, 30 minutes after premedication.

$\doteqdot$ †

Table 3 Analysis of variance for bronchodilator effect

\begin{tabular}{|c|c|c|c|c|c|}
\hline Source & $d f$ & SS & $M S$ & $F$ & $p$ \\
\hline $\begin{array}{l}\text { Between subjects } \\
\text { Between treatments } \\
\text { Placebo v active } \\
\text { Placebo } 1 v \text { placebo } 2 \\
\text { Linear dose-response } \\
\text { relationship } \\
\text { Quadratic dose-response } \\
\text { relationship } \\
\text { Residual }\end{array}$ & $\begin{array}{l}9 \\
4 \\
1 \\
1\end{array}$ & $\begin{array}{r}663 \cdot 52 \\
556 \cdot 32 \\
509 \cdot 60 \\
26 \cdot 45\end{array}$ & $\begin{array}{r}73 \cdot 72 \\
139 \cdot 08 \\
509 \cdot 60 \\
26 \cdot 45\end{array}$ & $\begin{array}{r}3 \cdot 92 \\
14 \cdot 37 \\
0.75\end{array}$ & $\begin{array}{c}0.010 \\
<0.001 \\
\text { NS } \\
\text { NS }\end{array}$ \\
\hline Total & 49 & $2496 \cdot 72$ & & & \\
\hline
\end{tabular}

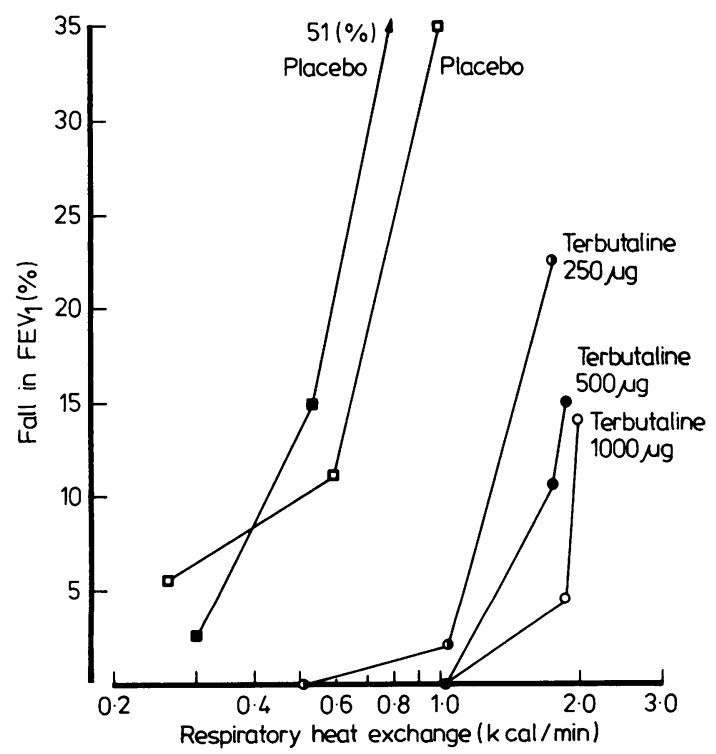

Log dose-response curves constructed after inhalation of cold air in subject 2, showing a progressive shift to the right with increasing doses of inhaled terbutaline.

Conversion: traditional to SI units-l $\mathrm{kcal} \approx 4.18 \mathrm{~kJ}$.
Table $4^{*}$ Analysis of variance for $\log P D_{10} R H E$

\begin{tabular}{lccccc}
\hline Source & $d f$ & $S S$ & $M S$ & $F$ & $p$ \\
\hline Between subjects & 9 & 6.108 & 0.679 & & \\
Between treatments & 4 & 6.961 & 1.740 & 10.63 & $<0.001$ \\
$\quad$ Placebo vactive & 1 & 6.775 & 6.775 & 41.39 & $<0.001$ \\
$\quad$ Placebo 1 v placebo 2 & 1 & 0.097 & 0.097 & 0.60 & $\mathrm{NS}$ \\
$\quad \begin{array}{l}\text { Linear dose-response } \\
\text { relationship }\end{array}$ & 1 & 0.373 & 0.373 & 2.28 & 0.053 \\
$\quad \begin{array}{l}\text { Quadratic dose-response } \\
\quad \text { relationship }\end{array}$ & 1 & 0.025 & 0.025 & 0.15 & $\mathrm{NS}$ \\
$\begin{array}{l}\text { Residual } \\
\text { Total }\end{array}$ & 26 & 4.256 & 0.164 & & \\
\hline
\end{tabular}

line caused an appreciable shift to the right of the dose-response curves (F 1,29 = 41.39, p < 0.001) (fig, table 4). In two subjects the response was abolished after $250 \mu \mathrm{g}$ terbutaline and in two others it was abolished after $500 \mu \mathrm{g}$. The remaining six subjects had at least a $10 \%$ fall in $\mathrm{FEV}_{\mathrm{l}}$ after terbutaline inhalation $(1000 \mu \mathrm{g})$ and hyperventilation induced by cold air. In these subjects $1000 \mu \mathrm{g}$ of terbutaline provided more protection than 500 $\mu \mathrm{g}$, which in turn provided more protection than $250 \mu \mathrm{g}$ (table 2). As a $\mathrm{PD}_{10}$ RHE value could not be obtained from four subjects at one or more drug dose levels, the values at these levels were treated as unknown for the purpose of analysis and a multivariate linear regression approach to an unbalanced two-way analysis of variance was used. There was a trend towards linear dose-response relationship with increasing doses of terbutaline but this did not reach significance $(F 1,29=2 \cdot 28, p=0 \cdot 053)$ (table 4).

The relationship between the bronchial responsiveness to RHE after placebo and the effect of terbutaline was examined. Complete inhibition of the response to RHE could not be achieved in any of the five most responsive subjects (initial $\mathrm{PD}_{10}$ RHE less than $1 \mathrm{kcal} / \mathrm{min}(4 \cdot 18 \mathrm{~kJ})$ ) at any dose of terbutaline, while the response in four of the five less responsive subjects (initial $\mathrm{PD}_{10}$ RHE greater than $1 \mathrm{kcal} / \mathrm{min}$ ) was completely inhibited. This difference was significant $(p=0.024)$. 
Side effects such as tremulousness and palpitations were not reported by any subject at any dose level of terbutaline.

\section{Discussion}

The results indicate that the dose of a $\beta$-adrenoceptor agonist required to inhibit the response to isocapnic hyperventilation induced by cold air, and presumably exercise, varies between asthmatic patients. In this study the response in two subjects was completely inhibited by one puff $(250 \mu \mathrm{g})$ of terbutaline and in two others by two puffs $(500 \mu \mathrm{g})$; in the remainder it was incompletely inhibited by four puffs $(1000 \mu \mathrm{g})$. Thus in clinical practice consideration should be given to adjusting the dose according to its effect and the severity of exercise.

Previous studies of exercise-induced asthma have usually examined the effect of a single dose of medication on a single period of exercise. In this type of study the result cannot be interpreted as accurately as when both drug and stimulus are delivered in precisely increasing amounts; this may account for some of the differences observed between the effect of the same drug in different subjects or of different drugs in the same subject. ${ }^{313-19}$ In the present study both terbutaline and hyperventilation were progressively increased. In addition, the response to hyperventilation was highly reproducible, with an intraclass correlation of 0.93 , indicting that only $7 \%$ of the differences in an individual subject on different days was due to inherent imprecision in the measurement. This precision is not found with exercise challenge, where the minute ventilation or conditioning of the inspired air has usually not been controlled; indeed, most studies of the effect of drugs on exercise induced asthma have not reported on the precision of the method. ${ }^{3+4151719}$

The response to cold air was expressed as the dose inducing a $10 \%$ reduction in $F E V_{1}\left(\mathrm{PD}_{10}\right)$ for two reasons. Firstly, in most previous studies of exercise-induced bronchoconstriction induced by exercise and by cold air a $10 \%$ fall in $\mathrm{FEV}_{1}$ or peak flow rates has been taken as indicting a response to the stimulus. ${ }^{152021}$ Secondly, in. this study the fall in $\mathrm{FEV}_{1}$ after inhalation of cold air did not reach $20 \%$ but it did reach $10 \%$ after administration of terbutaline in some subjects. In this study, as in a previous one, ${ }^{6}$ in those subjects in whom $\mathrm{PD}_{10}$ and $\mathrm{PD}_{20}$ values could be directly obtained the $\mathrm{PD}_{10}$ was about half the $\mathrm{PD}_{20}$, indicating that the $\log$ dose-response curves over this range of response are parallel.

The inhibition produced by terbutaline on the response to hyperventilation was associated with slight but significant bronchodilatation (table 3 ). This suggests that part of the protective effect of terbutaline was nonspecific and related to change in airway calibre. There was no evidence of a linear bronchodilator dose-response relationship with increasing doses of terbutaline; there was, however, a trend to a linear increase in protection, reflected in a progressive shift of hyperventilation $\bar{C}$ dose-response curves to the right. This suggests that some of the protection was specific to the pharmacological $\frac{\bar{s}}{D}$ effects of the drug.

Terbutaline was effective in shifting the dose-response \& curves after inhalation of cold air in all subjects studied. The mean $\mathrm{PD}_{10}$ RHE in the group on the two placebo days was 0.96 and $1.08 \mathrm{kcal} / \mathrm{min}$; this equals a minute $\vec{\omega}$ ventilation of about $30 \mathrm{l} / \mathrm{min}$, a challenge equivalent to walking briskly on a cold day. After inhalation of $\vec{x}$ terbutaline $1000 \mu \mathrm{g}$ the mean $\mathrm{PD}_{10}$ RHE was $2 \cdot 1 \mathrm{w}$ $\mathrm{kcal} / \mathrm{min}$, which equals a minute ventilation of about $60 . \overrightarrow{.}$ $\mathrm{l} / \mathrm{min}$, equivalent to running rapidly on a cold day. The mean $\mathrm{PD}_{10}$ RHE after inhalation of terbutaline 250 and $\frac{\bullet}{\omega}$ $500 \mu \mathrm{g}$ was 1.74 and $1.94 \mathrm{kcal} / \mathrm{min}$, which would allow 의

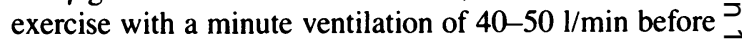
appreciable bronchoconstriction occurred.

The completeness of inhibition produced by terbutaline $\mathbb{D}_{\mathbb{D}}$ was related to the degree of responsiveness to hyperven- $\frac{\mathbb{D}}{3}$ tilation and respiratory heat exchange. The less the $\underset{\mathbb{D}}{\vec{D}}$ responsiveness the more complete the inhibition. The subjects were selected to give a range of increased $\vec{\oplus}$ responsiveness to hyperventilation. The most responsive ? developed bronchoconstriction after $7.5 \mathrm{l} / \mathrm{min}$ ventilation of cold air $(0.25 \mathrm{kcal} / \mathrm{min} \mathrm{RHE})$ and the least responsive developed bronchoconstriction after $60 \mathrm{l} / \mathrm{min}$ ventilation $(2.0 \mathrm{kcal} / \mathrm{min} \mathrm{RHE})$. The subjects also had relatively mild asthma in the sense that symptoms in all but one were $\mathbb{Q}$ controlled by salbutamol alone and $\mathrm{FEV}_{1}$ was greater than $\vec{F}$ $75 \%$ of predicted. Evidently therefore terbutaline ( 1000 응 $\mu \mathrm{g})$ will not completely inhibit the response to hyperventilation in more severely affected patients with a greater increase in non-specific bronchial responsiveness. Further work needs to be directed to more effectively inhibiting the response in such patients.

The trend to a linear increase in protection with increasing doses of terbutaline suggests that even higher doses might produce greater inhibition. In clinical $\bigcirc$ practice higher doses might be contraindicated because of side effects. A more practical method might be to응 combine two drugs such as a $\beta$-adrenoreceptor agonist $>$ and sodium cromoglycate; this, however, requires furthero study. While such studies are required in research, they may also be useful in certain patients in clinicalos practice-for example, in competitive athletes to deter- $N$ mine the most effect drug combinations for inhibiting exercise-induced asthma.

We thank the patients for participating in the study and 0 Drs J Dolovich and NL Jones for reviewing the manuscript. POB is fellow of the Medical Research $\Omega$ Council of Canada. The study was supported by a grant $\frac{\mathbb{Q}}{\AA}$ from Astra Pharmaceuticals Canada Ltd, Mississauga, Ontario. 


\section{References}

${ }^{1}$ Anderson S, Seale JP, Ferris L, Schoeffel R, Lindsay DA. An evaluation of pharmacotherapy for exercise induced asthma. J Allergy Clin Immunol 1979;64:612-24.

${ }^{2}$ Godfrey S, König P. Inhibition of exercise-induced asthma by different pharmacological pathways. Thorax 1976;31:13743.

${ }^{3}$ Morse JL, Jones NL, Anderson GD. The effect of terbutaline in exercise induced asthma. Am Rev Respir Dis 1976;113:89-91.

${ }^{4}$ Deal EC Jr, McFadden ER Jr, Ingram RH Jr, Strauss RH, Jaeger JJ. Role of respiratory heat exchange in production of exercise induced asthma. J Appl Physiol: Respirat Environ Exercise Physiol 1979;46:467-75.

5 Deal EC Jr, McFadden ER Jr, Ingram RH Jr, Breslin FJ, Jaeger JJ. Airway responsiveness to cold air and hyperpnea in normal subjects and in those with hay fever and asthma. Am Rev Respir Dis 1980;121:621-8.

6 O'Byrne PM, Ryan G, Morris M, McCormack D, Jones NL, Morse JLC, Hargreave FE. Cold air induced asthma: relationship to non-specific bronchial responsiveness to methacholine. Am Rev Respir Dis 1982;125:281-5.

${ }^{7}$ Ferrus L, Guenard H, Varden G, Varene P. Respiratory water loss. Respir Physiol 1980;39:367-81.

${ }^{8}$ West RC. Handbook of chemistry and physics. 58th ed. Cleveland, Ohio: CRC Press, 1977.

9 Winer BJ. Statistical principles in experimental design. 2nd ed. New York: McGraw Hill, 1971: 181.

${ }^{10}$ Kleinbaum DG, Kupper LL. Applied regression analysis and other multivariable methods. North Scitnate, Massachusetts: Duxbury Press 1978: 209-26, 244-88.
${ }^{11}$ Fleiss JL. Statistical methods for comparing rates and proportions. New York: Wiley Interscience, 1973:20.

12 Morris JF, Koski A, Johnson LC. Spirometric standards for healthy nonsmoking adults. Am Rev Respir Dis 1971;103:57-67.

13 Jones RS, Wharton MJ, Buston MH. The place of physical exercise and bronchodilator drugs in the assessment of the asthmatic child. Arch Dis Child 1963;38:539-44.

${ }^{14}$ Kiviloog J. The effect of pretreatment with atropine in exercise-induced bronchoconstriction. Pediatrics 1975;56:940-1.

15 Zielinski J, Chodosowska E. Exercise-induced asthma in patients with bronchial asthma: its prevention with an antihistaminic agent. Respiration 1977;34:31-5.

${ }^{16}$ Silverman M, Turner-Warwick M. Exercise-induced asthma: response to disodium cromoglycate in skin-test positive and skin-test negative subjects. Clin Allergy 1972;2:137-43.

${ }^{17}$ Pollock J, Kiechel F, Cooper D, Weinberger M. Relationship of serum theophylline concentration to inhibition of exercise-induced bronchospasm and comparison with cromolyn. Pediatrics 1977;60:840-4.

${ }^{18}$ König P. Clinical implications of bronchial lability in relation to asthma. University of London: Ph D thesis, 1974.

${ }^{19}$ Hartley JP, Charles TJ, Seaton A. Betamethasone valerate inhalation and exercise-induced asthma in adults. $\mathrm{Br} \mathrm{J} \mathrm{Dis}$ Chest 1977;71:253-8.

20 Jones RS. Assessment of respiratory function in the asthmatic child. Br Med J 1966; ii:972-6.

${ }^{21}$ Mellis CM, Kattan M, Keens TG, Levison H. Comparative study of histamine and exercise challenges in asthmatic children. Am Rev Respir Dis 1978;117:911-20. 